\title{
International trends in education and training in occupational hygiene is
}

\author{
Alex Burdorf \\ Institute of Occupational Health, Erasmus University, P.O. Box I738, 3000 DR Rotterdam, The Netherlands \\ Received 25 April 1994; revised 2 September 1994
}

\begin{abstract}
In many countries occupational hygiene has become an indispensable discipline in managing longterm risks to the health of workers. The international collaboration on education and training started with a workshop in Luxembourg in 1986 (sponsored by the EC and WHO). This meeting provided useful groundwork in defining the scope and function of training and education in occupational hygiene. Subsequent meetings in Geneva in 1989 and 1991 progressed many of the matters raised at the Luxembourg meeting. There is a fair agreement on the educational prerequisites for the professional occupational hygienist. Academic qualifications are regarded as essential since problem-solving, in contrast to rule-following, is best trained at academic level. For this reason a mandatory research project should be included in the curriculum. The general outline of an educational programme includes basic knowledge of physics, mathematics and chemistry, basic knowledge of supportive disciplines such as toxicology, epidemiology and biostatistics, risk analysis and engineering principles, and core and specialized topics in occupational hygiene such as measurement strategies, design techniques, health risk evaluation, principles of control inclusive ventilation, management and laws and legal requirements. Discussions pertains to the preferable educational routes, on the balance between methodology and professional practice, and the focus on prevention and engineering rather than exposure assessment. Currently, the International Occupational Hygiene Association has launched a programme for interchangeability and harmonization of the different certification schemes for professional occupational hygienists. International cooperation among educational resource centres should be strongly encouraged by exchange of students and faculty, as well as educational materials and information.
\end{abstract}

\section{Introduction}

The origin of the occupational hygiene discipline dates back to the late nineteenth century when engineers, chemists and physicians became involved in studying the working envi-

\footnotetext{
"Summary of a presentation at the 4th International Conference on Education and Training in Occupational Health in Amsterdam, 24-28 April 1994.
} 
ronment and its effect on worker's health (Hatch, 1960). In the early 1900s in the United States, occupational hygiene was part of occupational medicine. However, the first pioneers in the profession readily perceived the necessity of a close association with engineering disciplines. Since control of exposure required technical competence in manufacturing processes, the development of occupational hygiene towards engineering practice was a matter of course. This development is best illustrated by the first graduate programme for occupational hygienists, which was jointly established by the Schools of Engineering and of Public Health at Harvard University in 1927 (Hatch, 1960). The following important fields of knowledge were recognized: human toxicology and physiology, and industrial design and mechanical engineering. Since that time, medical sciences and engineering are the basic foundations of occupational hygiene.

With a time lag of approximately 25 to 30 years, a comparable development took place in the United Kingdom. It took another 25 years before the discipline rooted into Europe and in countries like Canada and Australia. During the 1980s, the occupational hygiene profession rapidly spread in the European countries. Currently, professional organizations are present in 12 countries in Europe, predominantly in member-states of the European Union and in Scandinavia. In many European countries principles of occupational hygiene have been enforced in guidelines and legislation. The European Union has indirectly promoted occupational hygiene by issuing many directives which describe what has to be done to identify, evaluate and control hazards at work. Several directives require that the principles of occupational hygiene he applied in the work environment, although without designating specifically the professional occupational hygienist (Burdorf, 1994).

A similar growth in the discipline has been observed in the Asian region. In the past decades several countries have rapidly transformed from a primarily agricultural country to a country with a large industrial sector. In countries such as Japan, Korea, China, and Taiwan the interest in occupational conditions has increased steadily and, consequently, occupational hygiene as a discipline has been instituted (Hay and Wei, 1994; Paik, 1994).

Depending on the historical development, occupational hygiene has established itself as a more technical-oriented discipline (United States, United Kingdom) or as a discipline strongly incorporated in occupational health care (Scandinavian countries, The Netherlands). Notwithstanding these differences, there is broad international agreement on the scope of occupational hygiene as the discipline of anticipating, recognizing, evaluating, and controlling health hazards in the working environment with the objectives of protecting workers' health and wellbeing. Worldwide, occupational hygiene is rapidly becoming an indispensable discipline in managing long-term risks to the health of workers (Guillemin, 1992).

\section{Features of the occupational hygiene profession}

Like many other professions, occupational hygiene has become a discipline with an international orientation because production, trade, and communication are not restricted by national frontiers. Occupational hygienists are increasingly faced with material safety data sheets compiled in other countries, they retrieve scientific and vocational literature from various international sources, they are involved in audits in subsidiaries abroad, and 
they are moving into the international consultancy market. This increasing international collaboration encourages a more harmonized approach and common methods, tailored to local needs and circumstances. Convergence in approach of occupational hygiene activities is also driven by Directives of the European Union and by supranational standards issucd by CEN and ISO.

In the past few years the domain of occupational hygiene has been extensively discussed at international meetings in Luxembourg in 1986, Geneva in 1989 and Geneva in 1991. The first meeting provided useful groundwork in defining the scope and objectives of the discipline, the minimum requirements for training and education of its practitioners, and the required quality of professional practice. The meeting resulted in a document describing the basic consensus on education and training in occupational hygiene (Corn and Corn, 1988). Subsequent meetings progressed many of the matters raised at the 1986 Luxembourg meeting. In 1992 the World Health Organization published a report focusing on the development of the profession and consequences for education and training (WHO, 1992). This document reports on the findings of an international workshop in Geneva in 1991, bringing together representatives from the World Health Organization, the Commission of the European Communities, the International Occupational Hygiene Association, and many national occupational hygienc socictics. In accordance with the scope and functions of a professional occupational hygienist, the role delineation of an occupational hygienist was defined. In summary, by virtue of their education and experience, occupational hygienists should be able to:

- identify exposure to hazardous agents at the workplace, predominantly of chemical, physical or biological origin, and, subsequently, develop an adequate measurement strategy to characterize exposure;

- evaluate work processes and methods, from the point of view of the possible generation and release/propagation of potentially harmful agents, with views to eliminating exposures or reducing them to acceptable levels;

- evaluate common health risks associated with exposure to hazardous agents at the workplace and perform a risk assessment for these agents;

- anticipate the health hazards that may result from work processes, operations and equipment, and accordingly advise on their planning and design.

These objectives refer to the basic knowledge and skills of occupational hygienists in the comprehensive practice; these professionals must be able to perform these activities without expert support or supervision.

Since occupational hygiene is by its nature applied and multidisciplinary, additional skills are required that allow for an occupational hygiene perspective in joint projects with adjacent disciplines in the field of occupational health and safety. Therefore, an occupational hygienist should also be able to;

- advise on planning and design of control measures, to supervise their implementation and to evaluate their effectiveness, alone or in collaboration with other specialized professionals;

- advise on the legal framework for working conditions and consequent actions necessary;

- educate, inform, train, and advise persons at all levels on aspects of occupational hygiene and hazard communication; 
- participate in overall risk assessment and management of an agent, process or workplace, and contribute to the establishment of priorities for risk management of agents with occupational or environmental impact.

These features of the occupational hygiene profession can be easily transferred into objectives of an occupational hygiene curriculum. The aforementioned report of the World Health Organization provides a general outline of a curriculum that complies to the necessary educational prerequisites for the designation of professional occupational hygienists (WHO, 1992).

Apart from this professional designation, various countries distinguish the separate qualification of the occupational hygiene technician with operational competence. The person holding such position is envisaged as one who is competent to carry out measurements of the work environment but is not able to make the interpretations, judgements, and recommendations required from a professional occupational hygienist. The technician grade includes knowledge and skills of instrumentation, sampling methods, appropriate hygiene standards, and general principles of occupational hygiene. Since requirements on education vary largely among different countries, this qualification is not taken into account in this paper.

\section{Curriculum for education and training}

The role delineation of the professional occupational hygienist requires specific areas of knowledge and a particular level of qualification. An important recommendation of the WHO report is that education and training should be at degree level (preferably at a master's level). An academic qualification is regarded essential since occupational hygienists must be capable to address new problems by applying knowledge and skills to situations not previously encountered in order to arrive at acceptable solutions or decisions. Problemsolving, in contrast to rule-following, is best trained at academic level. For the design of any education programme it is essential to understand that the learning of generalizable theoretical concepts does not necessarily result from nor require detailed study of all the specific problem areas (Hale et al., 1986; Hewitt, 1993). Hence, a careful balance between the wide range of topics in the discipline and in-depth study of critical subjects must be made to maintain intellectual development of the student (Sherwood, 1992).

A curriculum for an occupational hygiene education programme should, preferably, encompass three basic instruments of conveying knowledge and skills to students; courses, research, and period of probation. With respect to courses, which include lectures, practicals and exercises, three principal areas of knowledge are distinguished. A student must have sufficient knowledge of physics, mathematics, chemistry, and biology. These pre-entry areas of knowledge may be ensured by specifying entry requirements to the occupational hygiene courses or by offering undergraduate courses prior to starting the specific occupational hygiene courses. Basic areas of knowledge cover the core occupational hygiene topics such as principles of recognition of hazardous agents, measurement strategy, risk assessment, control principles, human toxicology, occupational diseases, epidemiology and biostatistics. Related areas of knowledge may be incorporated in these core courses or presented in separate courses, such as engineering and design, occupational safety, ergonomics, envi- 
ronmental hygiene, law, and management and communication. A third category of topics is intended to specialize in elective subjects such as industrial ventilation, noise control, radiation protection, and biohazards.

Given the emphasis on problem-solving in contrast to rule-following in the role delineation of professional hygienists, a research period is a vital element in an education programme in order to develop the student's ability to think critically and to respond quickly to new scenarios (Hewitt, 1993). A duration of at least six months is advised in order to achieve scientific education and training of sufficient depth. Students should write a thesis that shows that they are able to apply scientifically sound methods and techniques to occupational hygiene problems not previously encountered and arrive at acceptable solutions or decisions for these problems.

The curriculum on occupational hygiene should also have a component of practical work, including projects on relevant subjects and dealing with real situations of the comprehensive practice in occupational hygiene. Therefore, an internship is advocated. Students should get acquainted with the professional practice and experience how skills and knowledge are instrumental in arriving at acceptable solutions or decisions. This requires a period of probation of sufficient duration that exceeds the usual, short summer internship position (Sherwood, 1992).

\section{Discussion}

Education and training in occupational hygiene has been the subject of several international meetings in the past few years. International consensus on scope and contents of occupational hygiene curricula has emerged. The international developments in education and training in occupational hygiene and the main features of an education programme have been described in this article.

Hewitt has identified strong trends within universities involved in education and training (Hewitt, 1993). Certain trends may affect the current thoughts on appropriate education and training in occupational hygiene. Firstly, courses are increasingly becoming modular. Since an education programme should also train the "right attitude" to work on occupational hygiene problems, continuous interaction between teacher and student is regarded essential. A modular training may lead to courses that are too fragmented, that are too much oriented towards a body of knowledge, and that lack scientific depth. Although there is general reluctance to advocate an educational route through accumulating modules in sufficient numbers, some educational bodies have expressed the view that by adequate coordination and linking of the modular courses a consistent longterm training activity will emerge that provides a systematic route towards the professional qualification required (Gill, 1993).

Secondly, it is no longer a matter of course that education and research in occupational hygiene are strongly tied within university departments. Education programmes must ensure that occupational hygienists are properly equipped to deal with the rapidly changing work environment. This is best done by appropriate training in scientific methodology. Also, without strong links between education and research teachers will not be able to incorporate the latest concepts and up-to-date knowledge in the occupational hygiene curriculum. This 
may disturb the balance between methodological training and subject matter in the curriculum.

Apart from these future trends, discussion also pertains to the focus on prevention and engineering control rather than exposure assessment and epidemiology (Sherwood, 1992; Cherrie and Bord, 1991). It is argued that occupational hygiene should be redefined to emphasize its unique role in controlling those factors in processes, environment or work practices that may affect the workers' health. This requires quantification of risks and design of control measures, but overall a stronger orientation towards the engineering background of the discipline.

Despite the variety of educational backgrounds with considerable differences in structure and quality of education and training programmes, even within a particular country, the similarities in approach seem to outshine the differences. Throughout the world, there is fair agreement on the qualification of the core designation of the professional occupational hygienist. Existing national schemes for certification of occupational hygienists show a remarkably consistency. Qualifications include a degree in natural sciences or engineering with a sufficient amount of occupational hygiene courses, a successful pass on examinations, and about five years of experience in the comprehensive practice of occupational hygiene (Burdorf, 1994). Currently, the International Occupational Hygiene Association is reviewing the quality and qualification requirements of the existing certification schemes for professional occupational hygienists. It appears that interchangeability and harmonization is possible and much wanted. Although international agreement on a common approach may take some time, various options are under investigation, such as reciprocity (mutual recognition of national designations), interchangeability (cross-acceptance of national designations) and a common international standard (an umbrella scheme with one internationally accepted designation).

The development of occupational hygiene as a scientific discipline and a well-qualified profession depends largely on the quality of training and education programmes in occupational hygiene. Hence, international co-operation among educational resource centres should be strongly encouraged by the exchange of students and faculty, and also of educational materials and information. This would create a viable foundation for the enhancement of the discipline and will establish a true worldwide network of occupational hygienists.

\section{References}

Burdorf, A., 1994. Quality of the occupational hygiene profession in Europe. Ann. Occup. Hyg., 38, 939-944. Cherrie, J.W. and Bord, B.S., 1991. The joint education and training committee of the BOHS, IOH and BEBOH -A discussion on the future of occupational hygiene education and training in the UK. Ann. Occup. Hyg., 35: $665-670$.

Corn, M.W. and Corn, J.K., 1988. Training and education in occupational hygiene: An international perspective. Ann. Am. Conf. Govern. Ind. Hyg., 15.

Gill, F., 1993. Competency and the modular course. Ann. Occup. Hyg., 37: 435-440.

Guillemin, M.P., 1992. European initiatives and the occupational hygiene profession. Ann. Occup. Hyg., 36: 669674.

Hale, A.R., Piney, M. and Alesbury, R.J., 1986. The development of occupational hygiene and the training of health and safety professionals. Ann. Occup. Hyg., 30: 1-18.

Hatch, T.F., 1960. Training in industrial hygiene in the US. J. Occup. Med., 2: 321-324. 
Hay, D. and Wei, W., 1994. Development of occupational safety and health in the people's republic of China. Ann. Occup. Hyg., 38: 79-88.

Hewitt, P.J., 1993. Education and training in occupational hygiene in the United Kingdom. Ann. Occup. Hyg., 37: 321-325.

Paik, N.W., 1994. Kecent development of industrial hygiene in Korea. Ann. Occup. Hyg., 38: 95-97.

Sherwood, R.J., 1992. Cause and control: education and training of professional industrial hygienists for 2020. Am. Ind. Hyg. Assoc. J., 53: 398-403.

WHO (World Health Organization), 1992. Occupational hygiene in Europe: Development of the profession. WHO Regional Office for Europe, European Occupational Health Series No. 3, Copenhagen. 